\title{
PLANNING AND SIMULATION FOR RADIO ACCESS NETWORKS ON "SMALL CELLS" TECHNOLOGY FOR HETEROGENEOUS ENVIRONMENTS
}

\section{Gabriel Jaimes-Illanes}

\begin{abstract}
The document presents the planning and simulation of UMTS and LTE mobile telecommunications network by the use of Small Cells technology in heterogeneous environments solutions for real foray operators in Cochabamba to achieve efficiency in resource usage in a state of high traffic load of voice and data, and therefore achieve better utilities. The methodology is based on analytical development, planning, and simulation which take place in the first instance with the collection of information. In the following steps, the project requirements were identified, a vendor technical specifications comparison was made, and the Small Cell networks were designed by radio access network planning, cell distribution and dimensioning, transportation cadasters definition, technical equipment parametrization, and frequency plan determination. Finally a procedure of simulation for coverage predictions and design validation was made. It is concluded that the project is feasible and complies with technical requirements for land survey, services demand on voice and data, coverage for indoor or outdoor environments, mobility and transport users, parameters performance on RSCP, RSRP, RSRQ signal-to-noise ratio, capacity of users, specific scenario solutions and economic benefits on deployments.
\end{abstract}

Keywords: Wireless Mobile Telecommunication Systems, LTE, UMTS, Small Cells, Indoor, Outdoor, RSCP, RSRP, RSRQ, Capacity, Coverage.

DOI: 10.23881/idupbo.021.1-2i 